\title{
The research and development of Cross-fault site based information systems
}

\author{
Yue Wenchao ${ }^{1}$, Wang Ruiqi ${ }^{2}$, Wang Ning ${ }^{2}$ \\ 1Beijing Explo-Tech Engineering Co.,Ltd. \\ 2Xi'an University of Science and Technology College of Geomatics, Xi'an, 710054
}

\begin{abstract}
In view of location basic data that in cross-fault site based information management and use have incomplete, and many are the paper dielectric storages, inconvenient inquiry and use; venues of fault monitoring data and related foundation of geographic information location separates, does not help carrying on comprehensiveanalysis and other iss ues, discussed has established the cross-fault site based information system the method, to enhance the management, analysis and use cross-fault deformation monitor information. Key words-Earthquake prediction; Cross-fault; Deformation monitoring; GIS
\end{abstract}

\section{I .INTRODUCTION}

Earthquake is a super short-term geographical phenomenon, with distinct geo-spatial characteristics. In the earthquake zone, abnormal changes before earthquake in various geographical entities and geographic phenomena provide the possibility of earthquake prediction for people. Through the comprehensive analysis of various changes in the geographical information, people can advance in earthquake prediction, and earthquake losses will be reduced to a minimum. As an important tool of acquiring, storing, managing, and analyzing geospatial data, Geographic information systems (GIS) is the most powerful tool integrated analysis of earthquake information, so people have been exploring for years used GIS to aid in earthquake analysis and prediction.

For understanding mechanical process of earthquake faults, capturing earthquake precursors, a variety of cross-fault measurement has been carried out in China.Among them, deformation anomaly, usually as a very important indicator of seismic precursory information. At present, the deformation anomaly observed is a multi-source, is not full of crustal surface reaction activity, both external factors (natural phenomena, such as drought, freezing, temperature, hydrology etc.) and observation field itself factors (such as point stability, Line length and direction, whether to cross fault, fault activity and around the ground vegetation etc.).So,in the analysis of the fault information, how to correctly judge whether the factors of deformation anomaly earthquake precursors has become a pressing matter of the moment.

However, due to various reasons, currently prevailing the original site information is not complete, and many of information storage by the paper media that querying and using have a lot of inconveniences. In addition the fault monitoring data about the site and related basic geographic information separation, is not easy to make a comprehensive analysis of the monitoring data.

In this paper, through the research and development of the fault information system, discusses applying GIS technology to the daily earthquake analysis and prediction.

\section{II.THE OVERALL DESIGN OF THE SYSTEM}

The final objective to establish fault site based information system is using GIS method to integrating and analyzing the massive data (basic geographic data, seismic data, climate data), and combined with the deformation established analysis model, 
thus providing reliable information for earthquake prediction of deformation.

To achieve the following objectives:

1. Quantitative analysis and digital capture of cross-fault site information and Establishment of spatial database;

2.The establishment of quantitative analysis model.

Implements the following features:

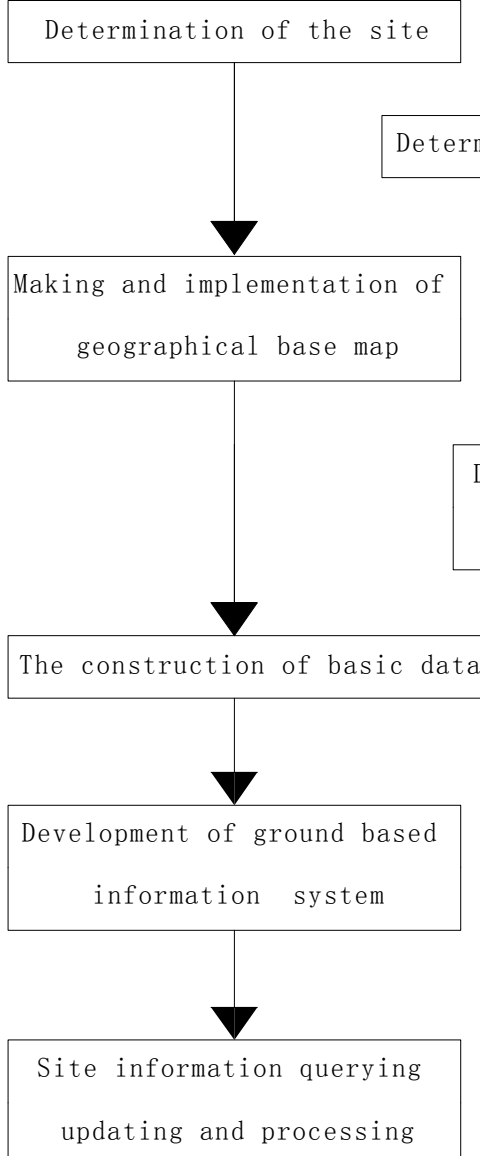

According to the leveling value, the baseline value, and the two baseline values calculate the fault activity

Basic time-space analysis and display function of fault deformation anomaly .

Reflect the spatial attribute and spatial relationship of cross-fault site

General idea of the system is as follows:

Establish the deformation factor system

Deformation factor data (including tables, images and video) collection, collation and analysis

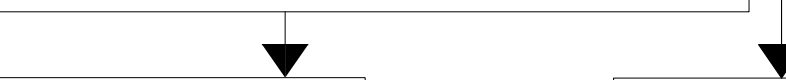

Establish deformation analysis model

Program development

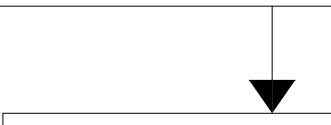

Calculating the value of influenc

factor of deformation

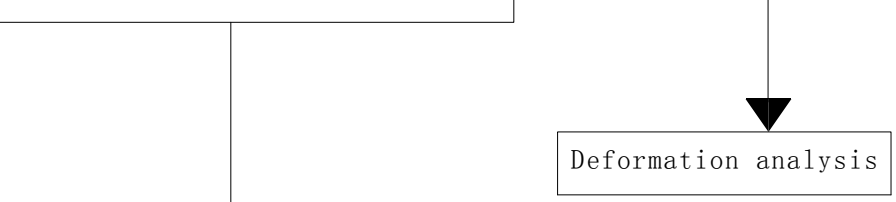

Preliminary results
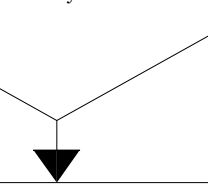

Report writing

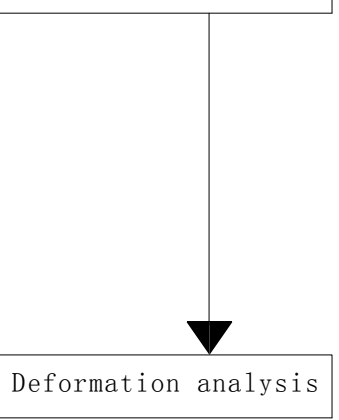

Fig. 1. cross-fault site based information system flowchart 


\section{DATABASE DESIGN}

Taking into account the cross-fault deformation influence factors always has a certain spatial relationship, in order to analyze crustal deformation, first need to build a survey area database, that is to store and manage the cross-fault survey area of fundamental geographic information and the measurement information.

Table 1. the northeastern margin of Qinghai-Tibet block across-fault database design table

\begin{tabular}{|l|l|l|l|}
\hline \multirow{4}{*}{ Type } & Layer name & Layer Content & Illustration \\
\hline \multirow{4}{*}{ Basic } & Relief map & $1: 500000$ relief map & Graphics \\
\cline { 2 - 4 } & Geomorphologicalmap & $1: 500000$ Geomorphological Map & Graphics \\
\cline { 2 - 4 } Geographic & vegetation map & $1: 500000$ vegetation map & Graphics \\
\cline { 2 - 4 } Map & Geological map & $1: 500000$ Geological map & Graphics \\
\cline { 2 - 4 } & Image map & SPAOT5 Image map & Graphics \\
\cline { 2 - 4 } & Administrative map & Administrative map & Graphics \\
\cline { 2 - 4 } Thematic & Natural regionalization map & Natural regionalization map & Graphics \\
\cline { 2 - 4 } & Monitoring area map & The survey area division & With attribute \\
\cline { 2 - 4 } & Tectonic line layer & The tectonic line distribution area measurement & With attribute \\
\cline { 2 - 4 } & Site distribution map & The measuring conditions of site distribution area & With attribute \\
\hline
\end{tabular}

Table2. Tectonic line structure of attribute table

\begin{tabular}{|l|l|}
\hline Number & \\
\hline Fault Name & \\
\hline The nature of the activities (sinistral, strike-slip, thrust) & \\
\hline Length $(\mathrm{km})$ & \\
\hline Formation age (Mesozoic-Cenozoic) & \\
\hline The latest activity (quaternary) & \\
\hline Seismic activity (along the fault occurred in 5.7 earthquake) & \\
\hline Occurrence (NEE/60) & \\
\hline Horizontal throw $(\mathrm{m} / \mathrm{T}): 2000 \mathrm{~m} / \mathrm{Q}$ & \\
\hline Vertical throw (m/T): $3000 \mathrm{~m} / \mathrm{Q}$ & \\
\hline Strike-slip rate ( $\mathrm{mm} / \mathrm{a}): 0.35$ & \\
\hline Pour-slip rate (mm/a) :0.95 & \\
\hline Paleo earthquake count & \\
\hline Characteristics of tectonic fracture belt & \\
\hline Geomorphologic features - geomorphic system (the broken & \\
\hline Geophysical characteristics (density, gravity gradient belt) & \\
\hline Magmatic intrusion & \\
\hline Determine the fault activity basis & \\
\hline Remark & \\
\hline
\end{tabular}


Table3. The site attribute table

\begin{tabular}{|l|l|l|}
\hline Site Name & & \\
\hline Administrative Region & & \\
\hline Fault Zone & & \\
\hline Area & & \\
\hline Elevation & & \\
\hline Circumstances & & \\
\hline Around the site engineering & & \\
\hline Temperature & & \\
\hline Precipitation & & \\
\hline Monitoring points count & & \\
\hline Measuring section count & & \\
\hline Baseline count & & \\
\hline Changes & & \\
\hline
\end{tabular}

In addition to build a site database, mainly used for basic monitoring information, analysis and monitoring results of geographic information management field and deformation the site.

Table 4 .the northeastern margin of Qinghai-Tibet block across-fault measurement site database design table

\begin{tabular}{|c|c|c|c|}
\hline Type & Layer Name & Layer Content & Illustration \\
\hline \multirow{2}{*}{ Basic } & General Situation & & \\
\hline & Relief map & 1:500 Relief map & Graphics \\
\hline Geographic & Geomorphologic map & 1:500 Geomorphologic map & Graphics \\
\hline \multirow[t]{2}{*}{ Map } & Image map & High resolution remote sensing image & Graphics \\
\hline & Tectonic line & & \\
\hline \multirow{7}{*}{$\begin{array}{l}\text { Thematic } \\
\text { Layers }\end{array}$} & Monitoring point distribution layer & & With attribute \\
\hline & Segment of Survey & & With attribute \\
\hline & Baseline Layer & & With attribute \\
\hline & Historical Earthquake & & \\
\hline & Around the Engineering & & \\
\hline & Precipitation Conditions & & \\
\hline & Temperature & & \\
\hline
\end{tabular}

\section{COMPLETION METHOD OF THE SYSTEM}

\section{1) Data Preparation}

Site refers to the zone where the monitoring points are.

The collection of site information should include the

following aspects:

(1)General situation of the site refers to of is whole venues of topographic maps or high-resolution mapping, photos and site geological background, and history earthquake, and geography, measuring district range, belongs to which fault and which district (text description) .

Property information: name, belongs district, and belongs fault, and site area, and monitoring points number, and measuring section number, and baseline number, and climate (temperature, precipitation, and pressure), and geological condition, and engineering condition closed to.

(2)Monitoring points information 
Including distribution map and information from photos for each monitoring point. Photographs include close-up photos and remote photos. Close-up photos mainly show the damage for monitoring points. Remote photos mainly show the environmental factors surrounding the monitoring points.

Monitoring points properties: point's id, location and photos

(3)Human factor

The surrounding environment and human factors, whether monitoring points is close to the road or in the mountains all will have some degree impact on the result. All above mainly rely on survey crew's observation .

(4)Measurement information past years

It's including high precision leveling and distance measurement.

Leveling, that is measuring the height difference between monitoring points . The survey road is closed leveling line and it's called measuring section between adjacent points.

Property information:measuring section, height difference measurement results in past years (table information, trend map information)
Distance measurement, that is measuring the distance between monitoring points.

The measure method is reciprocal observation. It's called baseline each between two points. Property information: baseline id, distance measurement results in past years (table information, trend map information).

2 ) Quantitative analysis and digital capture of cross-fault site information and Establishment of spatial database

Based on actual collection based information of fault site in the wild, in accordance with certain criteria to standardize data, collating, establishing a cross-fault survey sites information database, It provide a information platform for seismic data acquisition, management and updating.

Database includes all of the raw data, general situation of the site, geography, climate, temperature, site geological background, history earthquake, measuring section name, start time of surveying and other basic information . Data will be organized as follows:

Layer $\left\{\begin{array}{l}\text { Base Map } \\ \text { Database } \\ \text { Image Data } \\ \text { (Thematic data })\end{array}\left\{\begin{array}{l}\text { The District Foundation Database } \\ \text { Site database }\end{array}\right.\right.$

Fig. 2. the fault information database of based data organization method

3) System software development 
The system software is based on the VS2008 platform for development using $\mathrm{c}$ \# programming language, this stage realization of the system functions as follows:

1. The overlay of geographical map and floor plan import

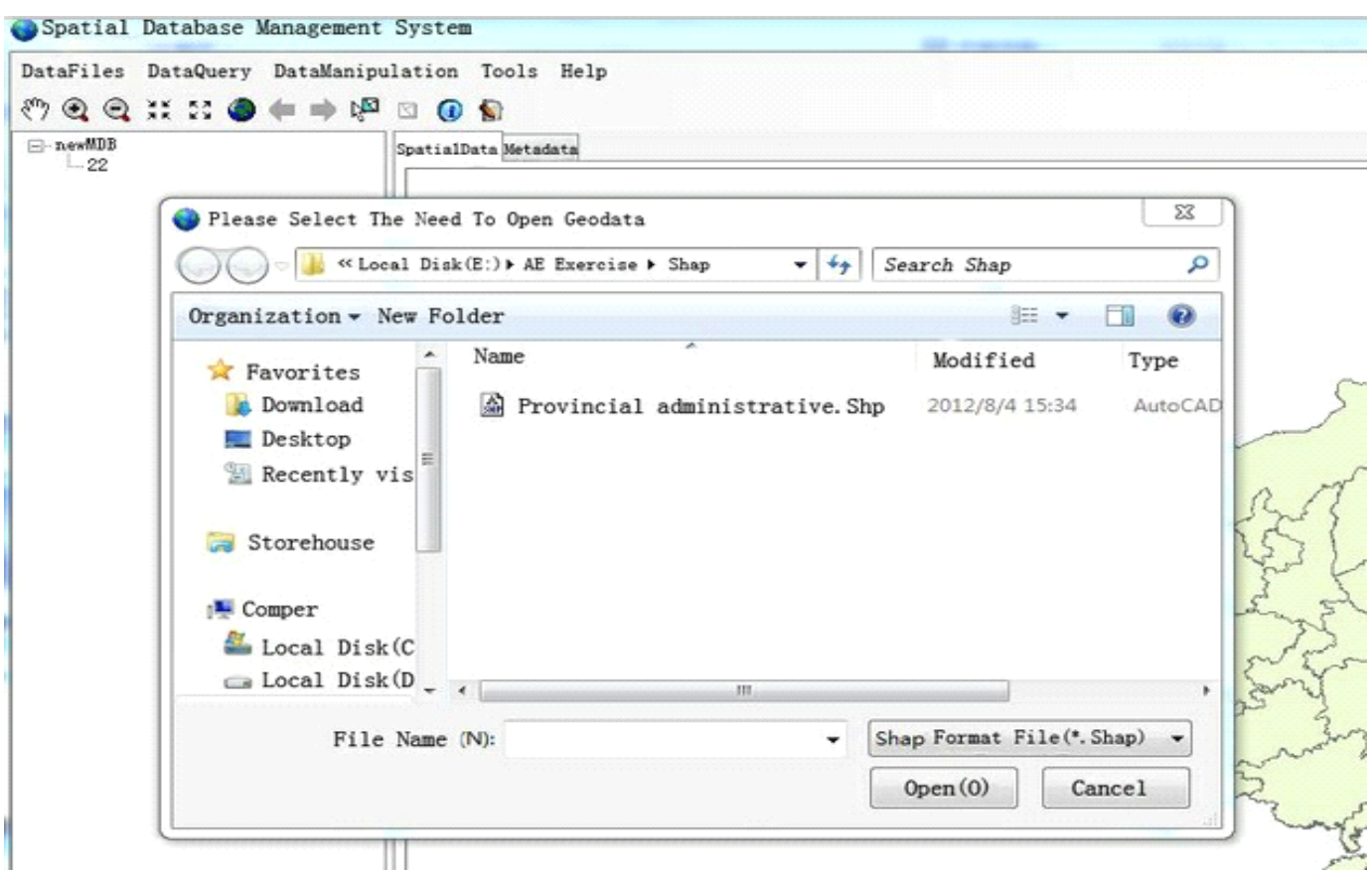

2.Established geographic information database of sites, change, maintenan

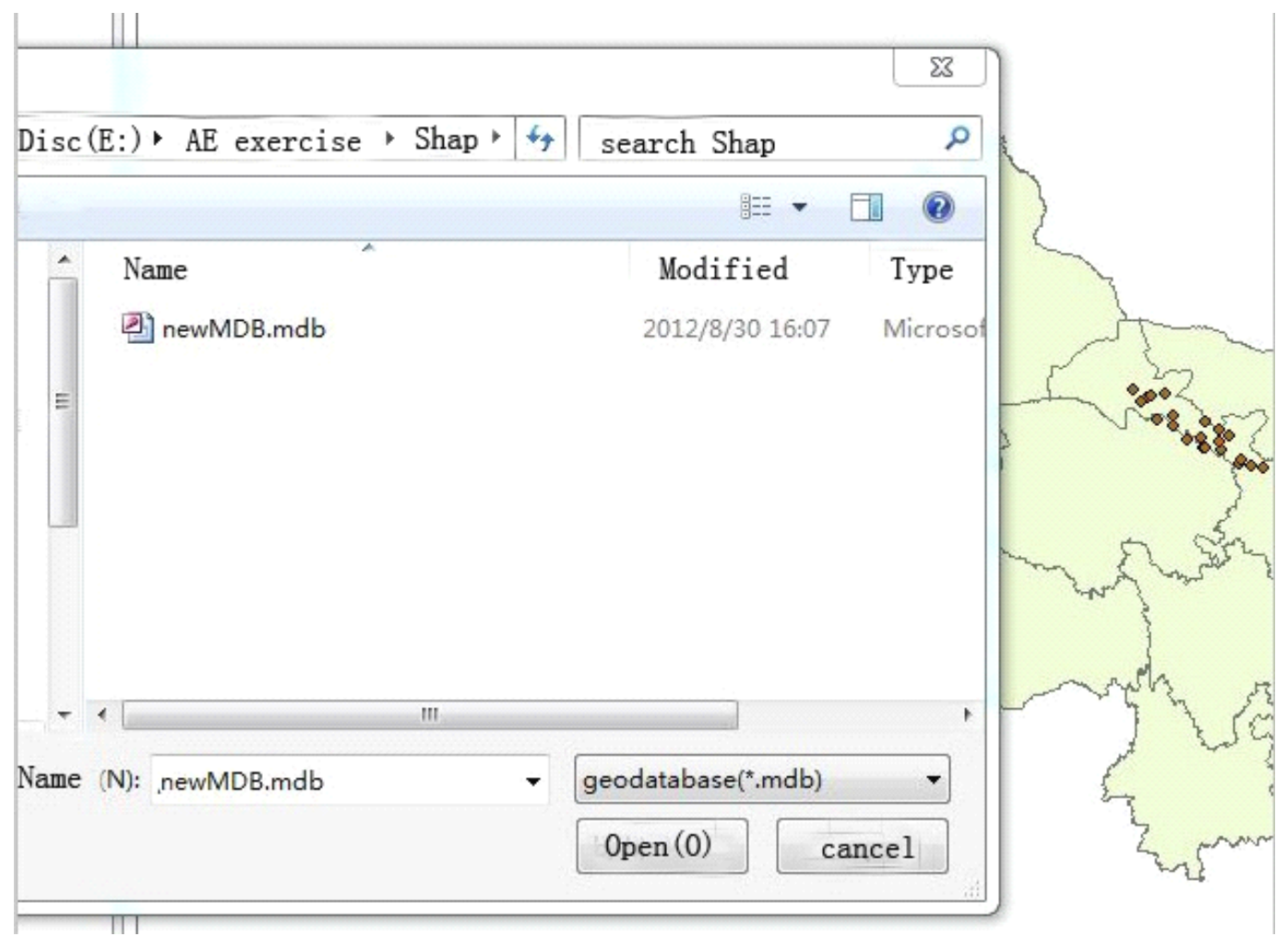


3. Grounds underlying geographic information from query, update, and simple analysis and processing

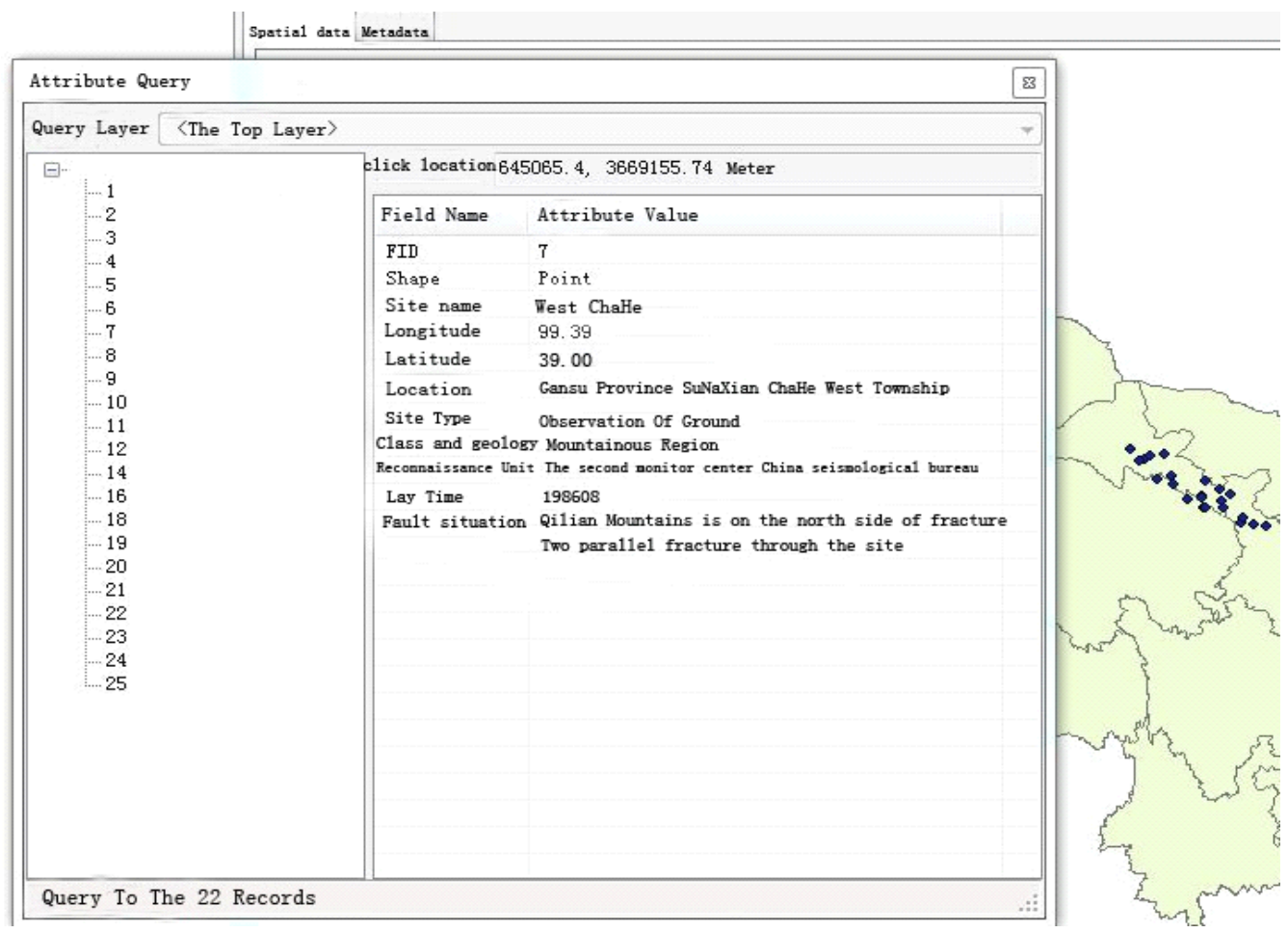

Chart file generated by the data files, has achieved to identify data patterns based on automatically generated as a function of a number of chart paper and visual clarity of expression, Xi Cha He Site baseline data, for example, the following figure:

\begin{tabular}{|c|c|c|c|}
\hline \multirow[t]{19}{*}{$\begin{array}{c}\text { G. west ChaHe } \\
(3-2) \\
(5 \leftarrow 4)\end{array}$} & \multicolumn{3}{|c|}{ data source visualization } \\
\hline & \multirow{18}{*}{ D } & Time & Dispersion \\
\hline & & 1988.0917 & -7928.5 \\
\hline & & 1989. 0322 & -7929.1 \\
\hline & & 1989.0719 & -7928.1 \\
\hline & & 1989. 0912 & -7928.2 \\
\hline & & 1989.1118 & -7927.5 \\
\hline & & 1990.0326 & -7927.5 \\
\hline & & 1990.061 & -7927.4 \\
\hline & & 1990.0831 & -7926.7 \\
\hline & & 1990.1121 & -7927.3 \\
\hline & & 1991.0324 & -7927.6 \\
\hline & & 1991.0721 & -7926.7 \\
\hline & & 1991.1112 & -7927.2 \\
\hline & & 1992. 0321 & -7927.4 \\
\hline & & 1992. 0719 & -7926.9 \\
\hline & & 1992.1113 & -7927.1 \\
\hline & & 1993.0327 & -7927.8 \\
\hline & & 1993. 0714 & -7927.3 \\
\hline
\end{tabular}

Fig. 3. ground-based data display 


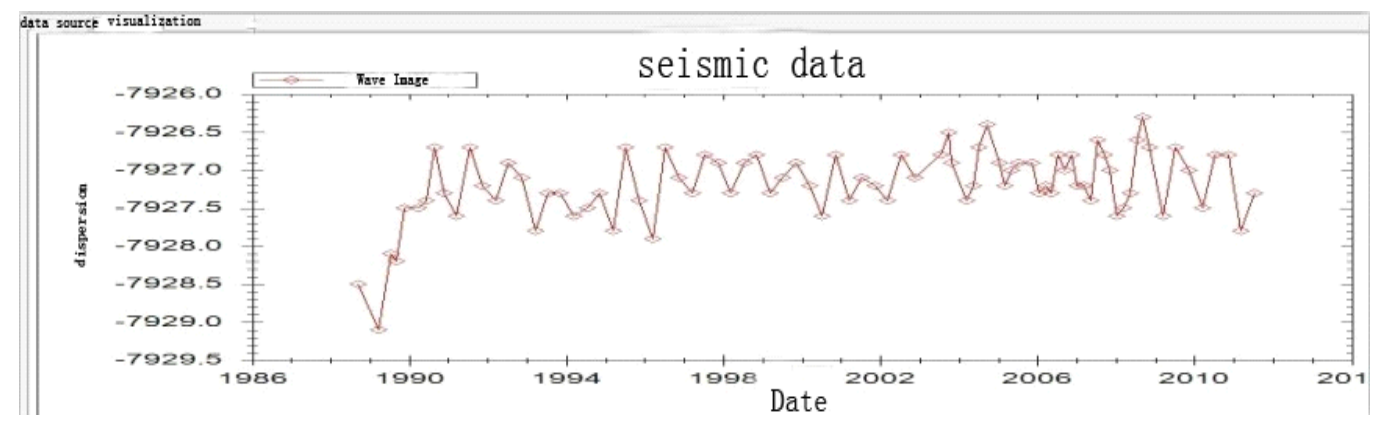

Fig. 4. base line data volatility

\section{V.CONCLUSION}

This cross-fault based information systems development, fundamental geographic database, Seismic special subject database, climate and hydrological databases. It can be integrated, analysis of massive data, combined with the establishment of the deformation model, comparative analysis, grey correlation analysis of the abnormal data, which gives an analytical report. Earthquake prediction expert analysis reports can help analyzing your data for

\section{REFERENCES:}

[1] Lou Guan Shou, Zhou Wei, Jin Peng et al. Factors across fault deformation interference survey [J]. Journal of Geodesy and geodynamics, 2010, Volume 30, supplement: 68-74

[2] Su Qin, et al. Gengda leveling anomaly and a magnitude 8 earthquake in Wenchuan [J]. Journal of Geodesy and geodynamics, 2009, Volume 29, supplement: $103-105$

[3] Li Zhixiong, et al. Earthquake, earthquake information recognition [J]. cross-fault deformation data in Daqing factory 1995, (3):222 - 227

[4] yellow Fuqiong, et al. The relationship between [J]. Journal of earthquake, deformation behavior and rainfall and groundwater eight house earthquake precursors or because of outside temperature, air pressure, destruction, geological and hydrological factors from the impact.

The system is easy to maintain, easy to post data updated in real-time, and Foundation information database also can join the site in picture data, video data, to facilitate on site in stereo, full range of observation and understanding, which is the innovation of the system.

mountain fault 2005, 27 (6):637—646 [5] Li Jie, et al. Analysis of abnormal high values of $[\mathrm{J}]$. Shanxi earthquake, Shandong Linqu leveling in Liujiazhuang, 2003, (1):24-26

[6] Li Jie, et al. Shandong across fault deformation anomaly tracking and seismic risk analysis $[\mathrm{R}] .2009$.

[7] Jiao Qing, et al. The effect of solar radiation on the [J]. crustal deformation and earthquake deformation measurements across faults in the Beijing area, 1993,(2):55-59

[8] Jiang Jingxiang, et al. Xinjiang Heizi across fault deformation measurement data analysis of abnormal [J]. northwestern Seismological Journal, 2002, $24(1): 42-48$

The first author: Yue Wenchao, Male, Engineer, Beijing Explo-Tech Engineering Co..Ltd., EMAIL:13581870325@139.com Tell : 13581870325 